\title{
Reseña de Pérez, Pilar, ¿Quién mata a Lucas Muñoz? Versiones sobre la vida, desaparición y muerte de un policía rionegrino. Buenos Aires, Teseo, 2019, 138 págs.
}

\author{
SANTIAGO GARAÑO (CONICET-UNLA-UNTREF) \\ Instituto de Ciencias Antropológicas / Facultad de Filosofía y Letras / Universidad de Buenos Aires \\ Universidad Nacional de Lanús \\ Universidad Nacional de Tres de Febrero \\ Ciudad de Buenos Aires, Argentina \\ sgarano@hotmail.com
}

Recibido: 26/03/2020 - Aceptado: 30/03/2020

¿Quién mata a Lucas Muñoz? es un libro urgente, escrito con la necesidad de producir un relato histórico acerca de la desaparición y muerte de un policía rionegrino, ocurrida entre el 14 de julio y el 10 de agosto del 2016 en la ciudad de San Carlos de Bariloche. ${ }^{1}$ La urgencia tiene el propósito de impugnar la versión oficial que ha negado la participación de la Policía en su asesinato. Pero, sobre todo, su autora busca incidir en el debate público para limitar el poder de policía y denunciar la impunidad que no solo ha rodeado este crimen sino a los numerosos casos de violencia policial, multiplicados desde la asunción de la Alianza Cambiemos, en diciembre de 2015. De ahí, el uso del tiempo presente en el título: Si no hay justicia, si no se sabe quiénes mataron a Lucas, esa muerte sigue siendo producida. Se vuelve un delito que no cesa de perpetrarse, como los crímenes de lesa humanidad cometidos durante la última dictadura argentina (1976-1983). No por nada, el libro se terminó de escribir en el contexto de la desaparición de Santiago Maldonado, ${ }^{2}$ ocurrida un año después de la de Muñoz.

La obra obtuvo la primera mención en el Concurso de Narrativa Testimonial "Rodolfo Walsh", organizado en forma conjunta por la Secretaría de Derechos Humanos de la provincia de Río Negro y el Fondo Editorial Rionegrino. Sin embargo, y pese a que estaba previsto en las bases de la convocatoria, la editorial provincial decidió unilateralmente no publicarlo -me atrevo a hipotetizar- debido a que se denuncia la participación de la Policía de Río Negro en la desaparición y asesinato de Lucas.

Junto con esta finalidad de incidencia política, el libro de Pilar Pérez es el producto de un trabajo serio de investigación, comprometido, riguroso y reflexivo, realizado por una historiadora experta en el estudio de la policía, investigadora del Consejo Nacional de Investigaciones Científicas y Técnicas (CONICET) y profesora de la Universidad Nacional de Río Negro.

Se relaciona con los intentos de ampliar la agenda de derechos humanos en la Argentina, un activismo que nació para denunciar los crímenes del terrorismo de Estado durante la última dictadura y, desde fines de los años '80 y principios de los '90, le fue sumando el debate al poder de policía, la denuncia de los casos de "gatillo fácil” y, ya en los 2000, el problema de la violencia carcelaria. Se inscribe en esa saga de luchas, pero también en una tradición de investigaciones que han develado la trama de la violencia policial y el lugar que le cabe al activismo de los familiares

\footnotetext{
${ }^{1}$ La versión digital puede descargarse en el siguiente link: https://www.teseopress.com/quienmata/

2 Un libro contemporáneo es: Escolar, Diego, Gendarmería. Los límites de la obediencia, Buenos Aires, SB, 2017. Se trata también de una obra escrita con la urgencia de incidir en el debate público frente a la desaparición forzada de Santiago Maldonado en manos de Gendarmería, durante un operativo de violenta represión a una protesta indígena en la Lof en resistencia Cushamen, Chubut, el 1 de agosto de 2017. Su autor, el antropólogo argentino Diego Escolar, inscribe ese acontecimiento que conmovió al país en la larga y corta historia de esta Fuerza de Seguridad.
} 
en esa lucha, tales como los de las antropólogas argentinas Sofía Tiscornia, ${ }^{3}$ María Pita $^{4}$ y Mariana Sirimarco $;{ }^{5}$ todos trabajos donde la investigación y el activismo tiene fronteras difusas.

Casos como el de Lucas, desaparecido y asesinado por la policía, hubo y habrá muchos. Sin embargo, su asesinato se convirtió en el caso, el que tuvo en vilo a la ciudad de San Carlos de Bariloche y a la provincia de Río Negro, el que se visibilizó en las calles y el que aún sigue presente en la memoria social. En esta línea, el libro nos muestra cómo en nuestro país algunos sucesos se transforman en casos emblemáticos. ¿Por qué sucede eso? No lo sabemos exactamente. Pero sí la historia reciente argentina nos da numerosas muestras de una tradición política que estructura su lucha colectiva a partir de casos-emblema, ${ }^{6}$ aun en lugares lejanos de las grandes capitales. Son esos casos los que logran darle visibilidad a formas naturalizadas y rutinarias de la violencia de Estado. Sobre el crimen de Lucas, el libro ilumina cómo la violencia institucional no solo se destina hacia aquellos sectores populares con los que las fuerzas de seguridad se vinculan cotidianamente, ${ }^{7}$ sino también incluye el desprecio hacia la vida de los policías indóciles, considerados seres matables. ${ }^{8}$

El libro muestra el parentesco profundo entre el pasado dictatorial y el presente de las violencias del Estado argentino contemporáneo. Ambos ejes se evidencian en la construcción del problema de investigación, en la reflexión de la autora y en la lucha en las calles barilochenses. Ejemplo de ello son: las fotos de Lucas como símbolo, en los carteles y pancartas que piden justicia, como en el caso de los desaparecidos durante régimen de facto; la similitud en los cantos de denuncia que se entonan en las marchas; equiparables estrategias de denuncia, como los "escraches"; y la centralidad de la lucha de los familiares. ${ }^{9}$

Tal como muestra Pérez, inscribir el caso de Lucas Muñoz en la saga de la lucha por los derechos humanos ha sido un trabajo complejo y árido. Mediante la reconstrucción y el análisis de este asesinato, la autora se anima a patear el tablero del sentido común humanitario, que no suele ser permeable a denunciar este tipo de crímenes. ¿Puede un policía ser una víctima? El libro demuestra que sí y solo sí puede ser clasificado socialmente como víctima si se lo inscribe en las luchas contra la violencia institucional y se abreva en el repertorio simbólico del movimiento de derechos humanos. En este sentido, la potencia y creatividad del lenguaje humanitario ha permitido incorporar este caso "incómodo". Esto permitió la reivindicación de la vida (y de la muerte) de un policía, volviendo a este ser matable en una vida que socialmente valió la pena. ${ }^{10}$ Además, todo este trabajo de memoria -en términos de Elizabeth Jelin- ${ }^{11}$ incorporó nuevos repertorios a la lucha, tales como la procesión desde Bariloche a la Línea Sur o el uso de las sirenas para denunciar la impunidad en torno al caso de Lucas.

\footnotetext{
${ }^{3}$ Tiscornia, Sofía, Activismo de los Derechos Humanos y Burocracias estatales. El caso Walter Bulacio, Buenos Aires, CELSEditores del Puerto, 2008.

${ }^{4}$ Pita, María Victoria, Formas de vivir y formas de morir. El activismo contra la violencia policial, Buenos Aires, CELS-Editores del Puerto, 2010.

${ }^{5}$ Sirimarco, Mariana, De civil a policía. Una etnografía del proceso de incorporación a la institución policial, Buenos Aires, Teseo, 2009; Sirimarco, Mariana (comp.), Estudiar la policia: la mirada de las ciencias sociales sobre la institución policial, Buenos Aires, Teseo, 2010.

${ }^{6}$ Este tipo de procesos es frecuente en el activismo por los derechos humanos; así lo hemos planteado en: Garaño, Santiago y Sarrabayrouse Oliveira, María José, "Aportes de la antropología política y jurídica al campo de los estudios sobre memoria y del pasado reciente", Cuaderno de Humanidades de la Universidad de Salta, N³0, 2019, págs. 44-63.

${ }^{7}$ Ver: Pita, María Victoria y Pacecca, María Inés, Territorios de control policial. Gestión de ilegalismos en la Ciudad de Buenos Aires, Buenos Aires, Facultad de Filosofía y Letras/Universidad de Buenos Aires, 2018.

${ }^{8}$ Esta expresión la tomo de: Butler, Judith, Vidas precarias. El poder de duelo y la violencia, Buenos Aires, Paidós, 2006.

9 Sobre este tipo de símbolos y rituales en el activismo de los derechos humanos, véase: Da Silva Catela, Ludmila, "Derechos humanos y memoria. Historia y dilemas de una relación particular en Argentina", en VIII Congreso Argentino de Antropología Social, Salta, 2006.

${ }^{10}$ Butler, Judith, Vidas precarias..., op. cit.

${ }^{11}$ Jelin, Elizabeth, Los trabajos de la memoria, Madrid, Siglo Veintiuno, 2002.
} 
Como las Madres de Plaza de Mayo en plena dictadura, los familiares de Lucas empezaron a pedir justicia en la más absoluta soledad, durante un invierno de Bariloche. Ese disparador fue el que conmovió a Pilar Pérez y la llevó a escribir este libro. En este sentido, este libro muestra el potente lugar del activismo de los parientes, aquellos que han politizado esa experiencia y se han transformado en familiares, esa potente categoría social e histórica que está detrás de las luchas contra la impunidad desde la última dictadura, pasando por las tragedias de Cromagnón ${ }^{12}$ y Once. Son esos familiares los que han tejido una red de afectos y de conocimiento que es previa a nuestras investigaciones y han incidido fuertemente en la producción de una verdad social sobre esos sucesos. Esta trama de luchas es la que aparece permanentemente en el libro de Pilar Pérez. Una trama reconstruida de modo indicial, detectivesco, pero a la luz de la vasta experiencia social, acumulada en estos años de democracia para lucha contra la impunidad en crímenes de Estado.

El libro busca discutir los umbrales del poder de policía y el lugar que históricamente los familiares han tenido en estas luchas sociales contra la impunidad que rodea a los crímenes de Estado. Considero que el aporte que desde las Ciencias Sociales podemos hacer a la reconstrucción del pasado reciente -en este caso, muy reciente- es contar esa historia de otra manera; también, plantear hipótesis que nos ayuden a comprender qué pasó con Lucas. Hipótesis que sean distintas a las que suelen llegarnos desde los medios hegemónicos o desde los rumores de ciudad.

Para Pilar Pérez, construir un caso implica ponerlo en contexto: contar el origen de Lucas en la Línea Sur (y cómo en Ramos Mexia, su lugar de nacimiento, pocos jóvenes se pueden desarrollar laboralmente); ubicar en el mapa de la ciudad de Bariloche y de la historia reciente argentina y de Chile; inscribir en el contexto de las políticas de seguridad de Cambiemos (y su letal doctrina "Chocobar"), de la historia de la policía de la Provincia de Río Negro (y su larga historia de represión y muerte) y de los estudios sobre policía. Esa densidad histórica se evidencia en una larga historia de desaparición de los seres molestos, disfuncionales y conflictivos, como los definió Pilar Calveiro. ${ }^{13}$ Recientemente, esto se ha notado, por un lado, en la ampliación del poder de policía y de construcción de los mapuches como "terroristas", desde diciembre de 2015; $\mathrm{y}$, por otro, en una violencia fuertemente generizada y sexualizada, cuyos destinatarios centralmente son los jóvenes varones pobres.

Por último, en términos éticos, este libro vence al miedo. El miedo a trabajar con un actor violento, arbitrario y discrecional, con el que todos los barilochenses conviven: la Policía de la provincia de Río Negro. La violencia institucional y los crímenes de Estado son mensajes que buscan infundir el terror e imponer la dominación estatal. Animarse a denunciarlos es un potente modo de combatirlos, al menos, como sabemos hacer los cientistas sociales: escribiendo historias que nunca se conformen con la versión oficial; tomando las distintas versiones que circulan; haciéndole buenas preguntas a las fuentes; y (re)armando relatos reflexivos y complejos sobre estos hechos sociales. Por todo ello, el libro de Pilar Pérez es una excelente muestra de una práctica de investigación fuertemente comprometida con la Memoria, la Verdad y la Justicia. Y, sobre todo, con la lucha contra la impunidad.

\footnotetext{
12 Ver: Pita, María Victoria, Formas de vivir y formas de morir..., op. cit. Sobre el lugar de los familiares en la masacre de Cromagnón, ver: Zenobi, Diego, Familia, politica y emociones. Las víctimas de Cromañón entre el movimiento y el Estado, Buenos Aires, Antropofagia, 2014.

${ }^{13}$ Calveiro, Pilar, Poder y desaparición. Los campos de concentración en Argentina, Buenos Aires, Colihue, 1998.
} 


\section{Santiago Garaño}

Licenciado y Doctor en el Área de Antropología por la Universidad de Buenos Aires. Integra el Equipo de Antropología Política y Jurídica, es parte de la coordinación de la Red de Estudios sobre Represión y Violencia Política (RER) y del Núcleo de Estudios sobre Memoria (IDES). Es Investigador Adjunto del CONICET y Profesor de las Universidades Nacionales de Lanús y Tres de Febrero. 